\title{
Natural background radiation dose rate levels and incidences of reproductive abnormalities in high radiation area in Abeokuta, Southwestern Nigeria
}

\author{
Nnamdi Norbert Jibiri", John Bamidele Famodimu \\ Radiation and Health Physics Research Laboratory, Department of Physics, University of Ibadan, Ibadan, Nigeria; \\ "Corresponding Author: ${ }^{*}$ jibirinn@yahoo.com, ${ }^{*}$ nnamdi.jibiri@mail.ui.edu.ng
}

Received 23 July 2013; revised 23 August 2013; accepted 30 August 2013

Copyright (C) 2013 Nnamdi Norbert Jibiri, John Bamidele Famodimu. This is an open access article distributed under the Creative Commons Attribution License, which permits unrestricted use, distribution, and reproduction in any medium, provided the original work is properly cited.

\section{ABSTRACT}

A 10 y (1999-2008) birth records from two public and most accessible maternity hospitals locally in the city of Abeokuta, Nigeria were used to investigate the possible association of high outdoor gamma radiation exposure on reproductive abnormalities in the city. From the delivery record of 11,923 births in the period under study, a total number of $\mathbf{4 8 5}$ incidences of reproductive abnormalities were recoded. These incidences comprise 228 multiple births, 190 still births and, 67 premature births. Using the available terrestrial gamma radiation exposure data for the city and different reproductive abnormalities, regression assessment was carried out using the Pearson Product Moment (PPM) correlation statistics. The correlation showed that the incidences of reproductive abnormalities and the radiation dose levels were negatively correlated and correlation coefficient values were very low for each of the reproductive abnormalities considered. Factors such as socio-economic potentials of patients, dietary and other environmental factors may have substantial influence on the reproductive defects in the area other than radiation. However, the present study has added to the radiometric information needed in understanding the relationship between natural outdoor radiation exposure and occurrences of reproductive abnormalities in areas of high radiation in the country.

Keywords: High Background Radiation; Gamma Radiation Dose Rates; Reproductive Abnormalities; Abeokuta Nigeria

\section{INTRODUCTION}

Assessment of impact of natural radioactivity on humans is very important because it will help in evolving national average for human environments, which can serve as a bench mark for introducing new technologies and lifestyles, thus helping to improve the state of health of man in areas with essentially high natural radiations. Due to the nature of the environment, man is continuously exposed to varying amount of ionizing radiation doses. It has been established that out of the total radiation dose received by man on the earth, about $96.1 \%$ is from natural sources while the remaining percentage is by man-made sources [1]. The main components of natural background radiations are extraterrestrial cosmic rays and the radiation due to the radioactivity of some primordial elements in the earth principally from decayseries elements, which are ${ }^{238} \mathrm{U},{ }^{232} \mathrm{Th}$ and non-decay ${ }^{40} \mathrm{~K}$. Apart from the inevitable natural background radiation sources, the radiation exposure to man in his environment can also arise from activities such as mining, radiological accidents and nuclear weapon testing. It has been a global interest to carry out the study of naturally occurring radiation and environmental radioactivity, and the results from such studies are being used to assess the radiation hazard of the exposed population. For example in Iran, studies [2,3] conducted on inhabitant of Ramsar which is an area with high level of natural radiation showed that there were no significant differences in the frequencies of any mental and physical disabilities as well as malignancies between residents of normal and high background radiation areas. Their results showed no significant increase in the frequency of death, abortion and mental depression among inhabitants in high background radiation area. Between August 1995 and June 2004, a clinical and cytogenetical observation of mal- 
formation as well as a comprehensive health audit survey was carried out in Kerala, India [4,5]. Out of the total number of 92,689 babies, the overall incidences of stillbirths and malformation recorded were $0.5 \%$ and $2.03 \%$ respectively. Multiple logistic regression analysis of the congenital malformations and stillbirths did not suggest any correlation with the radiation levels in this area. Furthermore, a study in Russia [6] also in high natural background radiation area did not have effect on the exposed population but altered the immune systems rather than inducing radiation disorders. Other similar studies have been carried out in Brazil and Egypt [7,8]. These assessments conducted in different parts of the world have been used to determine the impact of natural background radiation on birth defects, haematologic problems and other radiation induced diseases of the exposed population. While natural sources of radiation could be considered as low level exposure delivering low doses, high doses of ionizing radiation can lead to effects such as skin burns, hair loss, birth defects, illness, cancer, and death, depending on the dose and the period of time over which it is received [9]. Acute doses such as resulting from a serious accident involving nuclear materials can result in damage to the blood-forming organs, gastrointestinal tract, and central nervous system $[5,6]$. In Nigeria, the risks associated with environmental radioactivity have been carried to determine regional risks across the country $[9,10]$. The study showed that population in the northern part of Nigeria is associated with high radiation risks than that in the southwestern and Eastern regions [11]. In 2003, Obioha et al. [12] carried out assessment of incidences of reproductive defects due to natural radiations in two major towns, Enugu and Owerri, from the Southeastern part of the country. After the realization of Abeokuta as an area with high natural background radiation [10] principally due to its geological formation which is majorly a basement complex formation consisting of essentially granites [13] (Figure 1), various measurements and studies have been extensively carried out on the natural radioactivity levels of Abeokuta [14-16]. The natural radiation dose level in Abeokuta is more than four times higher than the world average value of 70 $\mu \mathrm{Sv} \cdot \mathrm{y}^{-1}$ and as such it has been classified as one of the high radiation areas in Nigeria [11]. However, no attempt has been made to use the data provided from the results of these various natural radioactivity level measurements to determine if the radiation dose rate levels from this area contribute to the incidences of reproductive abnormalities in the city. This present study is therefore being carried out to evaluate the incidences of reproductive abnormalities and the contribution of natural radiation dose levels to report cases in the city known for high radiations. Results are expected to add to the radiometric data on environmental radioactivity in the country and may equally be useful information to the Nigerian $\mathrm{Nu}-$ clear Regulatory Authority (NNRA) in environmental radiation protection policy formulation and implementation initiatives.

\section{PHYSIOGRAPHY AND GEOLOGY OF STUDY AREA}

The study area Abeokuta is located in the sub-humid tropical region of Southwestern Nigeria situated at coordinates: $7^{\circ} 9^{\prime} 39^{\prime \prime} \mathrm{N}, 3^{\circ} 20^{\prime} 54^{\prime \prime} \mathrm{E}$ and $7^{\circ} 9^{\prime} 39^{\prime \prime} \mathrm{N}, 3^{\circ} 20^{\prime} 54^{\prime \prime} \mathrm{E}$ latitudes and longitudes. As at 2005, Abeokuta and the surrounding area had a population of 593,140. The city enjoys a tropical climate with distinct wet and dry seasons with dry period of about 130 days. The mean annual rainfall and temperature are about $1270 \mathrm{~mm}$ and $28^{\circ} \mathrm{C}$ respectively while the estimated mean annual potential evaporation is $1100 \mathrm{~mm}$. The city is underlain by crystalline pre-Cambrian basement complex of igneous and metamorphic origin noted for their rather poor groundwater bearing properties and high contents of natural radioactive elements $[13,17]$. The area is known for scattered grey masses of granite and the city is drained mainly by River Ogun which passes through and divides the city into two, and the drainage pattern is dendritic. The geological map of the study area is shown in Figure 1.

\section{MATERIALS AND METHODS}

\subsection{Collection of Birth Records}

Two hospitals selected for the study were the most popular local medical care centers for the local population. They are Oba Ademola Maternity hospital and Ijaye State hospital. These two hospitals represent the most accessible and affordable medical care centers by low and medium income earners of the population and would therefore give records of patients who have been resident in the area for the past 25 years and whose livelihood equally revolves around the area. The people who live in areas of high natural radiation levels are of particular interest because they have been exposed abnormally to radiation over generations. As such there is a general perception that birth defects among the population in the high level natural radiation areas such as in Kerala are more than those in areas of normal background radiation [5]. The cases of incidences of reproductive abnormalities were obtained from the patient's admission registration records from the maternity ward of the hospitals. The registration numbers of the patients were then used to locate the case file to obtain all relevant and necessary information such as: occupation, level of education, place of birth, residential area, religion, age and the type of reproductive abnormality. The cases considered included multiple birth, stillbirth, premature birth, con- 


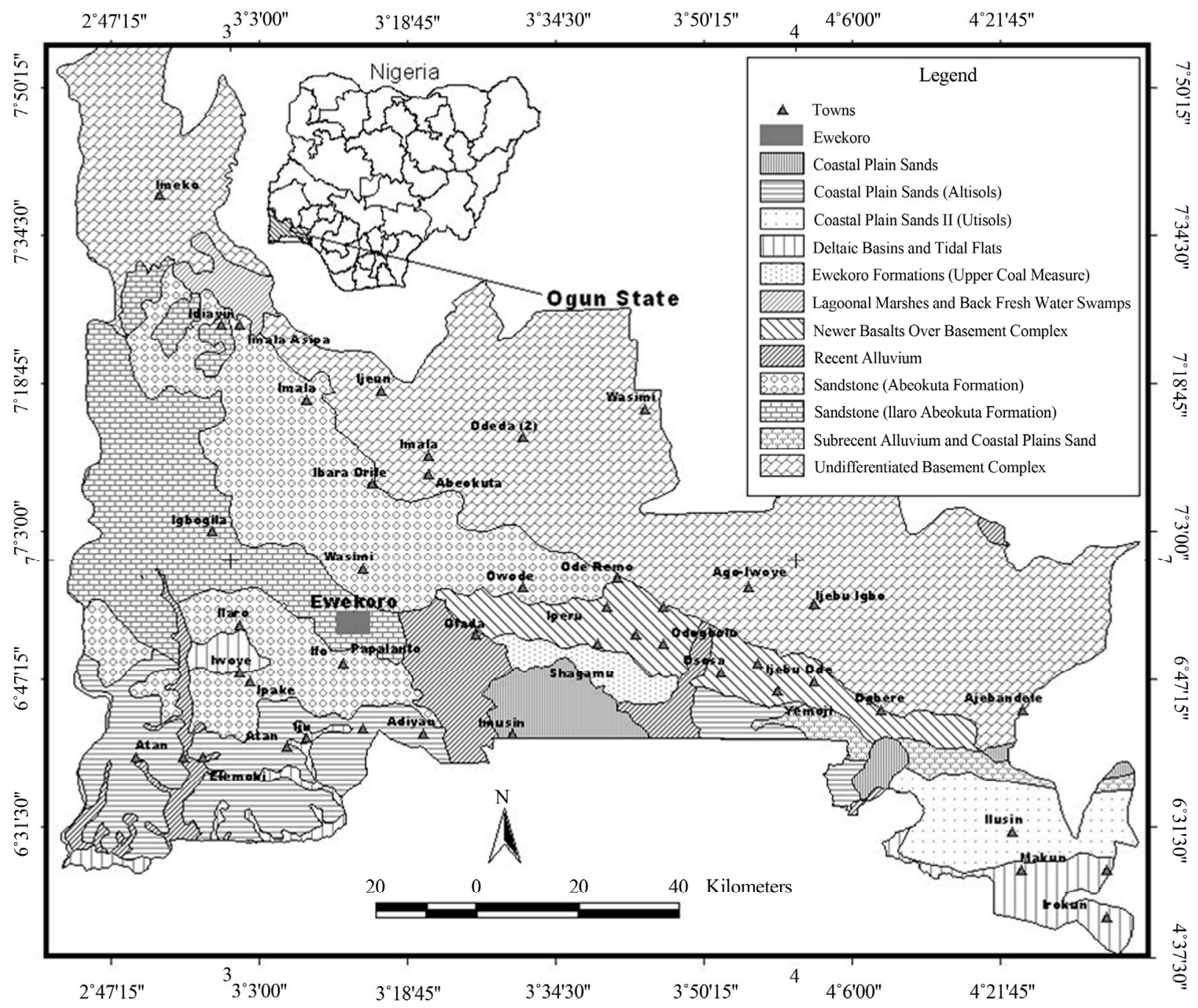

Figure 1. Geological map of Ogun State, showing Abeokuta city and its geological formation.

genital malformation and spontaneous abortion. A 10 years data of these birth defect records from each hospital was extracted for the study. The records of incidences per year per residential areas of the patients are presented in Table 1.

\subsection{Analytical Techniques}

A simple statistical treatment of the data was employed. The correlation between the annual effective dose and the birth defects observed from each location was determined using the Pearson Product Moment Correlation statistical method. For the purposes of definition birth defects are physical or physiological abnormalities that exist at the time of birth. In this work we have defined birth abnormality to represent incidences pertaining to births that are deviant from single and normal live births. Hence birth defects do not represent congenital abnormalities (teratogenic effects). In order to achieve the aim of this study the following hypotheses were tested:

1) H0: The natural radiation dose level in Abeokuta does not contribute to the reproductive abnormalities incidences in the selected hospitals (Null hypothesis).

2) $\mathrm{HO}_{2}$ : The natural radiation dose level in Abeokuta contributes to the reproductive abnormalities incidences in the selected hospitals (Alternative hypothesis).

\section{RESULTS AND DISCUSSIONS}

A total number of 178 birth defects were recorded out of a total number of 4453 deliveries taken at Oba Ademola Maternity hospital within the period of years considered while at Ijaye State hospital a total number of 307 birth defects were recorded out of a total number of 6470 delivery cases considered. The summary of distributions of the incidences of the birth defects from the two hospitals is summarized in Table 2 while Figure 2 shows the yearly distribution of the incidences.

The result of the survey presented above was related to 
Table 1. The 10-year reproductive abnormalities incidences at different locations of Abeokuta per the hospital record.

\begin{tabular}{|c|c|c|c|c|c|c|c|c|c|c|c|c|}
\hline \multicolumn{2}{|c|}{ Locations/Abnormality Type } & \multicolumn{11}{|c|}{ Number of incidences of abnormality per year } \\
\hline & & 1999 & 2000 & 2001 & 2002 & 2003 & 2004 & 2005 & 2006 & 2007 & 2008 & Total \\
\hline \multirow[t]{3}{*}{ Obantoko } & M.B & 2 & 1 & 0 & 2 & 1 & 0 & 1 & 1 & 0 & 1 & 20 \\
\hline & S.B & 1 & 1 & 0 & 0 & 2 & 0 & 1 & 1 & 0 & 2 & \\
\hline & P.B & 0 & 0 & 1 & 0 & 0 & 1 & 1 & 0 & 0 & 0 & \\
\hline \multirow[t]{3}{*}{ FCE Osiele } & M.B & 0 & 0 & 2 & 0 & 0 & 0 & 1 & 1 & 1 & 0 & 11 \\
\hline & S.B & 0 & 0 & 1 & 0 & 1 & 0 & 1 & 1 & 0 & 0 & \\
\hline & P.B & 1 & 0 & 0 & 0 & 0 & 0 & 1 & 0 & 0 & 0 & \\
\hline \multirow[t]{3}{*}{ Asero Estate } & M.B & 1 & 2 & 1 & 2 & 2 & 1 & 0 & 1 & 1 & 2 & 32 \\
\hline & S.B & 1 & 1 & 1 & 1 & 1 & 1 & 2 & 2 & 1 & 0 & \\
\hline & P.B & 0 & 0 & 1 & 0 & 0 & 1 & 1 & 0 & 1 & 1 & \\
\hline \multirow[t]{3}{*}{ Ake } & M.B & 1 & 1 & 1 & 1 & 0 & 1 & 2 & 1 & 0 & 1 & 20 \\
\hline & S.B & 0 & 1 & 1 & 1 & 1 & 2 & 0 & 1 & 1 & 0 & \\
\hline & P.B & 1 & 0 & 0 & 2 & 0 & 0 & 0 & 0 & 0 & 0 & \\
\hline \multirow[t]{3}{*}{ Olorunsogo } & M.B & 2 & 0 & 1 & 1 & 1 & 1 & 2 & 3 & 1 & 2 & 27 \\
\hline & S.B & 0 & 1 & 1 & 0 & 1 & 1 & 1 & 2 & 2 & 2 & \\
\hline & P.B & 0 & 1 & 1 & 0 & 0 & 0 & 0 & 1 & 0 & 0 & \\
\hline \multirow[t]{3}{*}{ Idi Aba } & M.B & 1 & 1 & 0 & 2 & 1 & 1 & 0 & 1 & 0 & 0 & 14 \\
\hline & S.B & 0 & 1 & 1 & 0 & 0 & 1 & 1 & 1 & 0 & 1 & \\
\hline & P.B & 0 & 0 & 1 & 0 & 0 & 0 & 1 & 0 & 0 & 0 & \\
\hline \multirow[t]{3}{*}{ Oke Sokori } & M.B & 0 & 0 & 1 & 2 & 1 & 0 & 0 & 1 & 0 & 1 & 13 \\
\hline & S.B & 1 & 0 & 1 & 0 & 2 & 0 & 0 & 0 & 1 & 0 & \\
\hline & P.B & 0 & 1 & 0 & 0 & 0 & 1 & 0 & 0 & 0 & 0 & \\
\hline \multirow[t]{3}{*}{ Kuto } & M.B & 0 & 1 & 2 & 2 & 0 & 1 & 2 & 4 & 5 & 3 & 41 \\
\hline & S.B & 1 & 1 & 3 & 1 & 0 & 1 & 2 & 2 & 2 & 3 & \\
\hline & P.B & 0 & 0 & 1 & 1 & 1 & 0 & 1 & 0 & 0 & 0 & \\
\hline \multirow[t]{3}{*}{ Oke Saje } & M.B & 0 & 1 & 0 & 1 & 0 & 1 & 1 & 2 & 1 & 1 & 18 \\
\hline & S.B & 0 & 0 & 0 & 1 & 2 & 1 & 1 & 1 & 1 & 1 & \\
\hline & P.B & 1 & 0 & 0 & 1 & 0 & 0 & 0 & 1 & 0 & 0 & \\
\hline \multirow[t]{3}{*}{ Aro } & M.B & 0 & 0 & 0 & 2 & 1 & 0 & 2 & 1 & 2 & 3 & 23 \\
\hline & S.B & 0 & 0 & 1 & 1 & 1 & 1 & 1 & 1 & 2 & 1 & \\
\hline & P.B & 0 & 1 & 0 & 1 & 0 & 0 & 0 & 0 & 0 & 1 & \\
\hline \multirow[t]{3}{*}{ Ago Oko } & M.B & 0 & 0 & 0 & 1 & 0 & 1 & 0 & 2 & 1 & 0 & 16 \\
\hline & S.B & 1 & 0 & 1 & 2 & 1 & 0 & 0 & 1 & 1 & 0 & \\
\hline & P.B & 0 & 0 & 0 & 0 & 0 & 1 & 0 & 0 & 1 & 0 & \\
\hline \multirow[t]{2}{*}{ UNAAB M.C. } & M.B & 0 & 0 & 1 & 1 & 0 & 1 & 1 & 2 & 2 & 2 & 22 \\
\hline & S.B & 0 & 0 & 0 & 2 & 1 & 0 & 2 & 1 & 2 & 1 & \\
\hline
\end{tabular}




\begin{tabular}{|c|c|c|c|c|c|c|c|c|c|c|c|c|}
\hline & P.B & 1 & 0 & 0 & 0 & 0 & 0 & 0 & 1 & 0 & 0 & \\
\hline \multirow[t]{3}{*}{ Isabo } & M.B & 0 & 0 & 1 & 2 & 1 & 0 & 0 & 1 & 3 & 1 & 17 \\
\hline & S.B & 0 & 1 & 0 & 0 & 0 & 1 & 0 & 2 & 1 & 3 & \\
\hline & P.B & 0 & 0 & 0 & 1 & 0 & 0 & 0 & 0 & 0 & 1 & \\
\hline \multirow[t]{3}{*}{ Onikolobo } & M.B & 0 & 0 & 0 & 1 & 1 & 1 & 1 & 1 & 3 & 1 & 20 \\
\hline & S.B & 0 & 1 & 0 & 2 & 1 & 0 & 1 & 1 & 1 & 1 & \\
\hline & P.B & 0 & 0 & 0 & 0 & 0 & 0 & 1 & 1 & 1 & 0 & \\
\hline \multirow[t]{3}{*}{ Oke Sabo } & M.B & 0 & 0 & 1 & 1 & 0 & 1 & 0 & 2 & 0 & 1 & 29 \\
\hline & S.B & 1 & 0 & 0 & 2 & 0 & 1 & 1 & 3 & 3 & 1 & \\
\hline & P.B & 0 & 0 & 0 & 1 & 0 & 0 & 0 & 1 & 1 & 0 & \\
\hline \multirow[t]{3}{*}{ GRA Ibara } & M.B & 0 & 0 & 0 & 1 & 1 & 0 & 1 & 2 & 1 & 2 & 18 \\
\hline & S.B & 0 & 0 & 1 & 0 & 0 & 1 & 0 & 3 & 1 & 2 & \\
\hline & P.B & 0 & 0 & 0 & 1 & 0 & 0 & 0 & 1 & 0 & 0 & \\
\hline \multirow[t]{3}{*}{ Mokola } & M.B & 1 & 1 & 1 & 0 & 0 & 1 & 1 & 1 & 1 & 0 & 14 \\
\hline & S.B & 0 & 0 & 0 & 1 & 0 & 0 & 0 & 2 & 1 & 1 & \\
\hline & P.B & 0 & 0 & 0 & 0 & 0 & 0 & 0 & 1 & 0 & 1 & \\
\hline \multirow[t]{3}{*}{ Ijeun Titun } & M.B & 0 & 1 & 1 & 0 & 0 & 0 & 3 & 2 & 3 & 4 & 30 \\
\hline & S.B & 0 & 0 & 1 & 0 & 0 & 1 & 2 & 3 & 4 & 1 & \\
\hline & P.B & 0 & 1 & 1 & 1 & 0 & 0 & 0 & 0 & 0 & 1 & \\
\hline \multirow[t]{3}{*}{ Ijaye } & M.B & 0 & 0 & 0 & 0 & 0 & 0 & 2 & 3 & 3 & 3 & 23 \\
\hline & S.B & 0 & 1 & 0 & 0 & 0 & & 1 & 1 & 1 & 2 & \\
\hline & P.B & 0 & 0 & 1 & 0 & 0 & 0 & 1 & 0 & 0 & 1 & \\
\hline \multirow[t]{3}{*}{ Llafenwa } & M.B & 1 & 1 & 0 & 0 & 0 & 1 & 1 & 3 & 2 & 2 & 24 \\
\hline & S.B & 0 & 0 & 0 & 1 & 0 & 1 & 2 & 2 & 1 & 2 & \\
\hline & P.B & 0 & 1 & 0 & 0 & 1 & 0 & 2 & 0 & 0 & 0 & \\
\hline \multirow[t]{3}{*}{ Iberekodo } & M.B & 0 & 1 & 2 & 1 & 0 & 1 & 1 & 3 & 1 & 2 & 26 \\
\hline & S.B & 1 & 0 & 1 & 0 & 0 & 0 & 1 & 3 & 2 & 2 & \\
\hline & P.B & 0 & 0 & 0 & 0 & 0 & 1 & 1 & 2 & 0 & 0 & \\
\hline \multirow[t]{3}{*}{ EHS Asero } & M.B & 0 & 1 & 1 & 0 & 1 & 1 & 2 & 5 & 1 & 1 & 27 \\
\hline & S.B & 0 & 0 & 0 & 0 & 0 & 0 & 1 & 4 & 3 & 3 & \\
\hline & P.B & 0 & 1 & 0 & 0 & 0 & 0 & 1 & 1 & 0 & 0 & \\
\hline Total & & 20 & 28 & 37 & 47 & 27 & 33 & 58 & 100 & 65 & 70 & 485 \\
\hline
\end{tabular}

M.B - Multiple birth, S.B — Still birth, P.B — Premature births.

the data available on radiation dose levels measured in the city of Abeokuta by Farai and Vincent [15]. The result of the measurement done by Farai and Vincent [15] showed that the estimated average value of the annual effective dose in Abeokuta is $0.45 \pm 0.27 \mathrm{mSv} / \mathrm{y}$, this value was in agreement with the estimated average value of $0.40 \pm 0.26 \mathrm{mSv} / \mathrm{y}$ obtained in the earlier reports $[14,16]$. Using the patient records in Table 2 the data collected from the hospitals were regrouped and correlation analysis was carried out. The correlation coefficient values obtained for each reproductive abnormality and the radiation dose levels is presented in Table 3 while the 
Table 2. Reproductive abnormalities at the locations and corresponding annual effective dose rates.

\begin{tabular}{|c|c|c|c|c|c|}
\hline Locations & Annual Effective Dose (mSv) $[11,15]$ & Multiple births & Still births & Premature births & Total abnormality \\
\hline Obantoko & 1.64 & 9 & 8 & 3 & 20 \\
\hline FCE Osiele & 0.96 & 5 & 4 & 2 & 11 \\
\hline Asero Estate & 0.35 & 15 & 13 & 4 & 32 \\
\hline Ake & 0.30 & 9 & 8 & 3 & 20 \\
\hline Olorunsogo & 0.39 & 13 & 11 & 3 & 27 \\
\hline Idi Aba & 0.39 & 7 & 5 & 2 & 14 \\
\hline Oke Sokori & 0.37 & 6 & 5 & 2 & 13 \\
\hline Kuto & 0.23 & 20 & 16 & 5 & 41 \\
\hline Oke Saje & 0.58 & 8 & 7 & 3 & 18 \\
\hline Aro & 0.75 & 11 & 9 & 3 & 23 \\
\hline Ago Oko & 0.49 & 5 & 6 & 2 & 16 \\
\hline UNAAB M C & 0.33 & 10 & 9 & 3 & 22 \\
\hline Isabo & 0.31 & 8 & 7 & 2 & 17 \\
\hline Onikolobo & 0.53 & 9 & 8 & 3 & 20 \\
\hline Oke Sabo & 0.19 & 14 & 11 & 4 & 29 \\
\hline GRA Ibara & 0.51 & 8 & 7 & 3 & 18 \\
\hline Mokola & 0.20 & 7 & 5 & 2 & 14 \\
\hline Ijeun Titun & 0.41 & 14 & 12 & 4 & 30 \\
\hline Ijaye & 0.40 & 11 & 9 & 3 & 23 \\
\hline Lafenwa & 0.27 & 11 & 9 & 4 & 24 \\
\hline Iberekodo & 0.50 & 12 & 10 & 4 & 26 \\
\hline EHS Asero & 0.29 & 13 & 11 & 3 & 27 \\
\hline
\end{tabular}

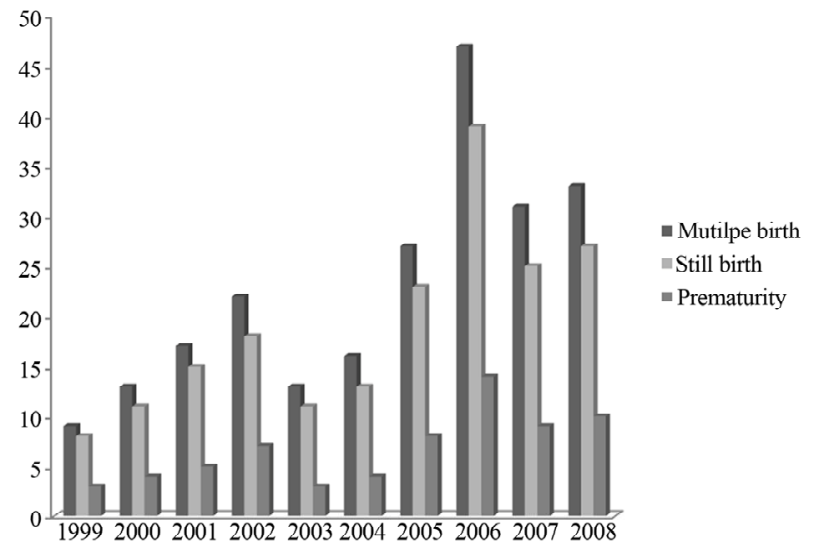

Figure 2. The annual distribution of birth defects in the selected hospital in Abeokuta.

correlation matrix is presented in Table 4.

Figures 3-5 showed the scatter diagrams for each correlation between the variables considered. The corre-
Table 3. The correlation between the annual effective dose and reproductive abnormalities.

\begin{tabular}{ccc}
\hline Reproductive abnormalities & Correlation coefficient $(\mathrm{r})$ & $\mathrm{r}^{2}$ \\
\hline Multiple birth & -0.069 & 0.00480 \\
Still birth & -0.061 & 0.00370 \\
Premature birth & -0.026 & 0.00068 \\
Total & -0.049 & 0.00240 \\
\hline
\end{tabular}

lation coefficient value for each of the reproductive abnormality was very low and the values of $r^{2}$ were less than $10 \%$. This is an indication of poor correlation between the radiation dose and the reproductive abnormalities. As could be seen from the correlation analysis no strong correlation was established hence an indication that no obvious relationship between the incidence of reproductive abnormality with radiation dose levels. From the observations, the null hypotheses formulated 
Table 4. Correlation matrix.

\begin{tabular}{cccccc}
\hline & $\begin{array}{c}\text { Effective } \\
\text { Dose }\end{array}$ & $\begin{array}{c}\text { Multiple } \\
\text { Birth }\end{array}$ & Still Birth & $\begin{array}{c}\text { Premature } \\
\text { Birth }\end{array}$ & $\begin{array}{c}\text { Total Birth } \\
\text { Defect }\end{array}$ \\
\hline $\begin{array}{c}\text { Effective } \\
\text { dose }\end{array}$ & 1 & & & & \\
$\begin{array}{c}\text { Multiple } \\
\text { Birth }\end{array}$ & -0.29231 & 1 & & & \\
Still Birth & -0.25944 & 0.980874 & 1 & & \\
$\begin{array}{c}\text { Premature } \\
\text { Birth }\end{array}$ & -0.17328 & 0.893024 & 0.890928 & 1 & \\
$\begin{array}{c}\text { Total Birth } \\
\text { Defect }\end{array}$ & -0.26977 & 0.994902 & 0.992796 & 0.917821 & 1 \\
\hline
\end{tabular}

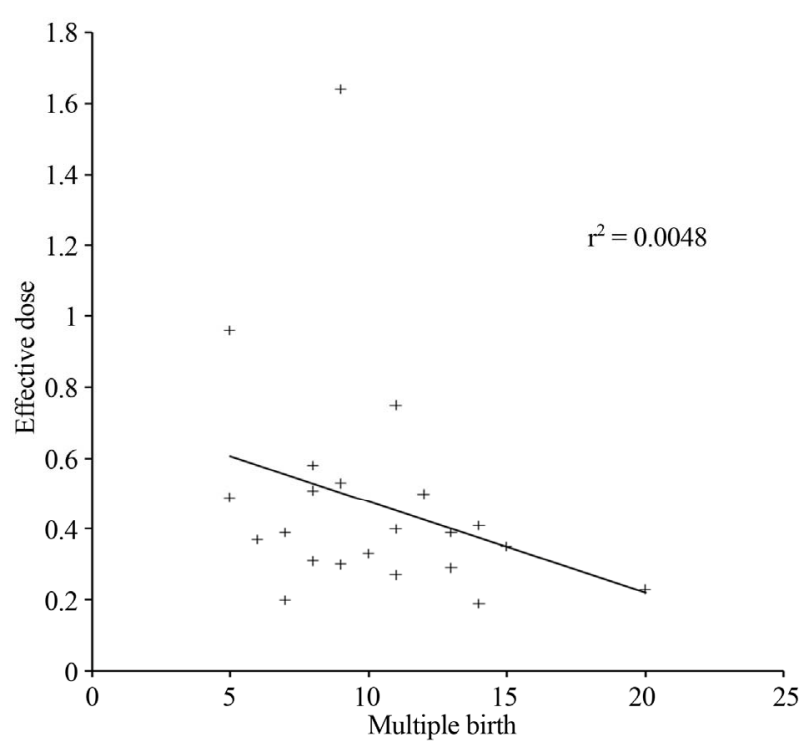

Figure 3. The correlation of effctive dose and multiple births in the city.

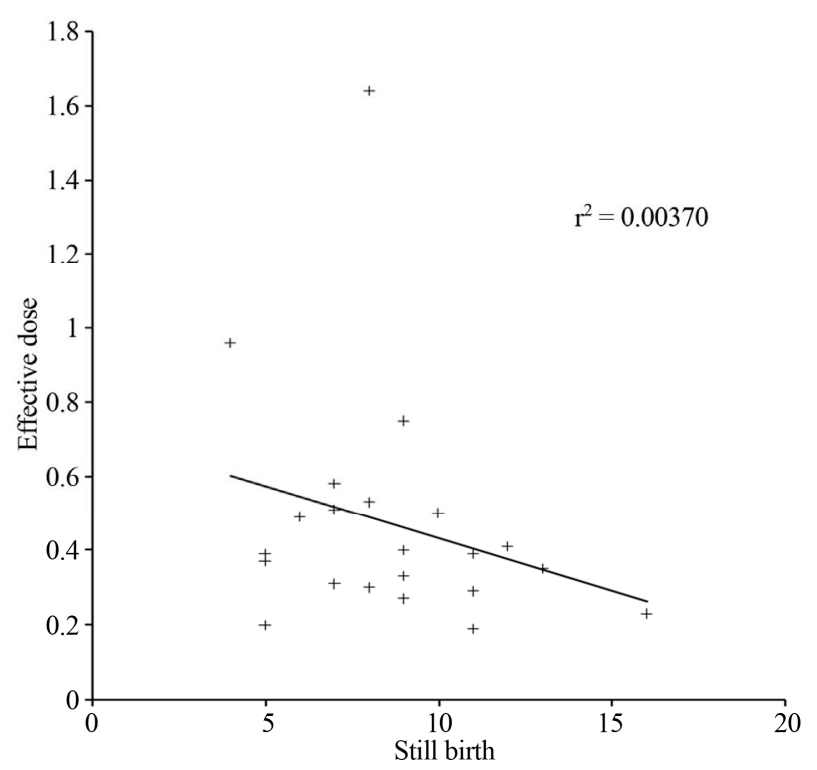

Figure 4. The correlation of effctive dose and still births in the city.

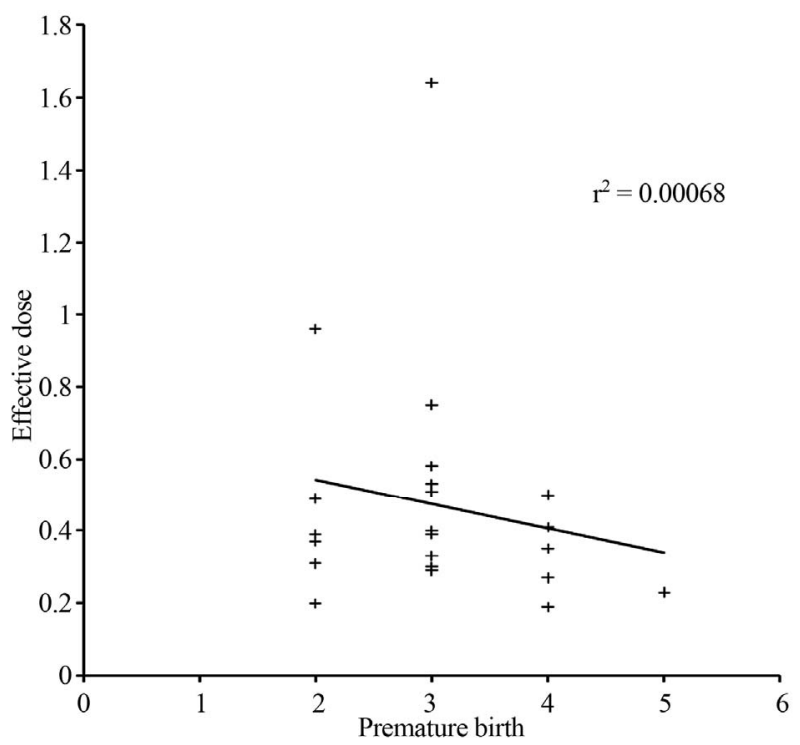

Figure 5. The correlation of effctive dose and premature births in the city.

are set aside as follows:

$\mathrm{HO}_{2}$ : The natural radiation dose level from Abeokuta contributes to the reproductive abnormalities incidences observed is hereby rejected on the ground that there is no correlation between the radiation dose and reproductive abnormalities observed.

$\mathrm{HO}_{1}$ : The natural radiation dose level from Abeokuta does not contribute to the reproductive abnormalities incidences observed, is hereby accepted on the same ground.

This study did not specifically show differences based on socio-economic parameters but according to a similar study by Obioha et al. [12] it is arguable that there are no valid demographic indications for demarcation of our population into various socio-economic classes. However, how a person lives is determined largely by where he lives and greatly influences his disposition and accessibility to medical care. The frequency of reproductive defects was found almost doubled in the low to medium income groups as low income mothers are usually multigravidae and therefore more prone to reproductive defects. Indeed there is a large population of low income mothers who do not frequently visit the hospitals except when reproductive difficulties arise. However, it has been now shown that there are no excess stillbirths or birth defects among the newborns in the HLNRA of Kerala [18]. According to studies [18,19], there is no scientific evidence to show that population groups exposed to low level radiation may suffer any harmful effect. The congenital anomalies in newborns found in high level natural radiation areas (HLNRA) is not different from or their frequency higher than those found in any other part where the radiation level is normal. 
Some of the anomalies are lower in HLNRA probably because of higher literacy, health awareness, and practices in the study population. A similar trend could be seen in this study following Table 2, higher incidences of these abnormalities were found to occur in the areas with low level radiation dose rates (Kuto, Asero, Ijeun Titun, Oke sabo) than in the high dose rate areas (Obantoko, FCE Osiele and Aro). This present study is therefore in agreement with the findings of other research on soil radioactivity and incidences of cancer [10] and those of natural radiation and birth abnormalities in Eastern cities in Nigeria [12]. These studies [10-12] showed no startling differences on background gamma radiation levels and incidences of cancer and birth defects. Within the limitations of this present study, it has added information on the radiometric knowledge needed in understanding the relationship between natural outdoor radiation exposure and occurrences of cancer and reproductive abnormalities in areas of high radiation in the country. Importantly this study will help set a basis for future research efforts in this direction.

\section{CONCLUSION}

The importance of an adequate knowledge of the natural background radiation in an environment is highly essential for correct assessment of the radiological effect of the natural radiation dose levels on the exposed population. A 10 years hospital based data on the incidences of reproductive defects in Abeokuta city known for high radiations have been used to investigate the contributions of natural background radiation to reproductive abnormalities in the city. The records of data were classified into different reproductive abnormalities and were related to the available data on terrestrial radiation dose rate levels in the city. The correlation of the two sets of data showed that the natural radiation dose levels in the city played no glaring role on incidences of reproductive defects within the study area and the period considered.

\section{REFERENCES}

[1] Chongankar, M.P., Eppen, K.P. and Ramachanadara, T.V. (2003) Profiles of doses to population living in high background radiation areas in Kerala. Journal of Environmental Radioactivity, 71, 275-297.

http://dx.doi.org/10.1016/S0265-931X(03)00174-7

[2] Abel-Ghandy, H.A., El-Zakla, T. and Hassan, A.M. (2000) Environmental radioactivity of some Egyptian sand samples. Romanian Journal of Physics, 54, 213-223

[3] Ghiassi, N.M., Zakeri, F., Assaei, R.G. and Kariminia, A. (2004) Long term immune and cytogenic effects of high level natural radiations on ramsar inhabitants in Iran. Journal of Environmental Radioactivity, 74, 107-116. http://dx.doi.org/10.1016/j.jenvrad.2003.12.001

[4] Samavat, H., Farzad, J., Hossein, M., Mahood, H. and Ali,
S.M. (2005) Examination of the health effects of high natural background radiations among the residents of ramsar in Iran. International Congress Series, 1276, 8-12.

[5] Padmanabhan, V.T., Sugunan, A.P., Brahmaputhran, C.K., Nanidi, K. and Pavithran, K. (1998) Heritable anomalies among the inhabitants of normal and high background radiations in Kerala: Result of a cohort study. Journal of Clinical Densitometry, 1, 379-383

[6] Thampi, M.V., Cheryan, V.D., Jaikarishem, G., Gas, B. and Kurien, C.J. (2004) Investigation of health effect of human population exposure in the area with high level natural radiation in Kerala, Southwest Coast of India. International Congress Series, 1276, 162-165.

[7] Sokolova, I.I., Malysheva, Z.V. and Tiutiunnik, I.F. (1998) Ecology and female reproductive system. Meditsina Truda Promyshlennaia Ekologiia, 9, 18-22.

[8] Ashraf, E.M., Khater, R.M. and Higgy, M.P. (2001) Radiological impact of natural radioactivity in Abu-Tartor phosphate deposit in Egypt. Journal of Environmental Radioactivity, 55, 255-267. http://dx.doi.org/10.1016/S0265-931X(00)00193-4

[9] Jibiri, N.N. (2001) Assessment of health risk associated with terrestrial gamma radiation dose rate levels in Nigeria. Environment International, 27, 21-26. http://dx.doi.org/10.1016/S0160-4120(01)00039-3

[10] Farai, I.P., Obed, R.I. and Jibiri, N.N. (2006) Soil radioactivity and incidence of cancer in Nigeria. Journal of Environmental Radioactivity, 90, 29-36. http://dx.doi.org/10.1016/j.jenvrad.2006.06.003

[11] Farai, I.P. and Jibiri, N.N. (2000) Baseline studies of terrestrial outdoor gamma dose rate levels in Nigeria. $\mathrm{Ra}$ diation Protection Dosimetry, 88, 247-254.

http://dx.doi.org/10.1093/oxfordjournals.rpd.a033042

[12] Obioha, F.I., Okonkwo, P.O., Agwu, K.K. and Okoye, I.J. (2003) Assessment of the impact of background gamma radiation on reproductive defects in two major Igbo towns of Nigeria. West African Journal of Radiology, 10, 4-7.

[13] Obed, R.I., Farai, I.P. and Jibiri, N.N. (2005) Population dose distribution due radioactivity levels in 18 cities across Nigeria. Journal of Radiological Protection, 25, 305-312.

[14] Farai, I.P. and Ademola, J.A. (2005) Radium equivalent activity concentrations in concrete building blocks in eight cities in Southwestern Nigeria. Journal of Environmental Radioactivity, 79, 119-125

[15] Farai, I.P. and Vincent, U.E. (2006) Outdoor radiation level measurement in Abeokuta. Nigeria Journal of Physics, 18, 121-126.

[16] Jibiri, N.N., Farai, I.P. and Alausa, S.K. (2009) Radiological hazard indices due to activity concentrations of radionuclide in farm soil from two high background radiation areas in Nigeria. International Journal of Low Radiation, 6, 79-95. http://dx.doi.org/10.1504/IJLR.2009.028529

[17] Jones, H.A. and Hockey, R.D. (1964) The geology of part of Southwestern Nigeria. Geological Survey of Nigeria Bulletin, 31, 1-101.

[18] Parthasarathy, S.K. (2004) No major birth defects found 
in high level natural radiation areas of Kerala. http://www.thehindu.com/sci-tech/

[19] Balachandar, V., Kumar, R.K.M., Prakash, V., MohanaDevi, S., Kumar, B.L., Manikantan, P., Sasikala, K., Malathi, J., Brahmanadhan, M., Khanna, D. and Selvasekara- pandia, S. (2011) Evaluation of genetic alterations in inhabitants of a naturally high background radiation and Kudankulam nuclear power project site in India. Asian Pacific Journal of Cancer Prevention, 12, 35-41. 